\title{
Broad Clinical Manifestations of Polygenic Risk for Coronary Artery Disease in the Women's Health Initiative
}

Shoa L. Clarke, MD, PhD, ${ }^{1,2^{*}}$ Matthew Parham, MS, ${ }^{3 *}$ Aladdin H. Shadyab, $\mathrm{PhD},{ }^{4}$ Simin Liu, $\mathrm{MD}, \mathrm{ScD},{ }^{5}$ Charles Kooperberg, $\mathrm{PhD},{ }^{6} \mathrm{JoAnn}$ E. Manson, MD, DrPH, ${ }^{7}$ Catherine Tcheandjieu, DVM, PhD, ${ }^{1,2}$ Themistocles L. Assimes, MD, $\mathrm{PhD}^{1,2,3}$

${ }^{1}$ VA Palo Alto Health Care System, Palo Alto, CA

${ }^{2}$ Department of Medicine, Division of Cardiovascular Medicine, Stanford University School of Medicine, Stanford, CA

${ }^{3}$ Department of Epidemiology and Population Health, Stanford University School of Medicine, Stanford, CA

${ }^{4}$ Herbert Wertheim School of Public Health and Human Longevity Science, University of

California, San Diego, La Jolla, CA

${ }^{5}$ Department of Epidemiology, Brown University, Providence, RI

${ }^{6}$ Fred Hutchinson Cancer Research Center, Seattle, WA

${ }^{7}$ Department of Medicine, Brigham and Women's Hospital, Harvard Medical School, Boston,

MA

* These authors contributed equally

Corresponding Author

Themistocles L. Assimes, MD, PhD

1070 Arastradero Road, Suite 300, Palo Alto, CA 94304

Phone: 650-498-4154

tassimes@stanford.edu 


\section{Abstract}

Background: The genetic basis for coronary artery disease (CAD) risk is highly complex. Genome-wide polygenic risk scores (PRS) can help to quantify that risk, but the broader impacts of polygenic risk for CAD are not well characterized.

Methods: We measured polygenic risk for CAD using the metaGRS, a previously validated genome-wide PRS, in a subset of genotyped participants from the Women's Health Initiative (WHI) and applied a phenome-wide association study framework to assess associations between the PRS and broad range of blood biomarkers, clinical measurements, and outcomes.

Results: Polygenic risk for CAD was associated with a variety of biomarkers, clinical measurements, behaviors, and diagnoses related to traditional risk factors, as well as riskenhancing factors such as elevated lipoprotein(a), increased central adiposity, earlier age of menopause, and rheumatoid arthritis. Analysis of adjudicated outcomes showed a graded association between atherosclerosis related outcomes, with the highest odds ratios being observed for the most severe manifestations of CAD. Higher polygenic risk for CAD was also associated with decreased risk for any incident cancer, breast cancer, and invasive breast cancer but a younger age of death.

Conclusion: Polygenic risk for CAD has broad clinical manifestations, reflected in biomarkers, clinical measurements, behaviors, and diagnoses. Some of these associations may represent direct pathways between genetic risk and CAD while others may reflect pleiotropic effects independent of CAD risk. 
medRxiv preprint doi: https://doi.org/10.1101/2021.06.15.21258993; this version posted June 18, 2021. The copyright holder for this preprint (which was not certified by peer review) is the author/funder, who has granted medRxiv a license to display the preprint in perpetuity.

\section{Introduction}

Coronary artery disease (CAD) is a complex phenotype, and the genetic basis for CAD risk is similarly complex..$^{1}$ To date, $>200$ loci have been implicated in CAD risk through genome-wide association studies (GWAS). ${ }^{2,3}$ These loci interact through a diverse set of biological pathways, and many loci have no apparent relevance to traditional risk factors for CAD. Furthermore, genetic variants that associate with CAD also associate with other phenotypes, suggesting extensive underlying pleiotropy. ${ }^{2,3}$ The complexity of genetic risk for CAD is further highlighted by recent advances in the construction of polygenic risk scores (PRS). Contemporary scores that incorporate variants across the whole genome, including variants outside of known CAD loci, outperform scores that are constructed only from variants at known CAD loci. ${ }^{4,5}$ Studying such genome-wide PRS for CAD may allow for improved understanding of the genetic basis for CAD risk and new insights into the implications polygenic risk beyond CAD.

One approach to assessing the impact of polygenic risk for $\mathrm{CAD}$ has been to measure associations between a CAD PRS and biobank-derived phenotypes. ${ }^{6,7}$ A primary advantage of this approach is the large number of participants in such biobanks. However, a limitation of this method is lack of precision for some outcomes, particularly those inferred from electronic health records. Further, biobank studies have typically combined prevalent and incident disease and may have limited follow up after enrollment. Thus, a complementary approach to biobank analyses is to examine well-phenotyped longitudinal cohorts.

Here, we sought to identify traits and outcomes associated with polygenic risk for CAD by taking advantage of the high-quality data collected as part of the Women's Health Initiative (WHI). We aggregated data collected over $\sim 25$ years as part of either clinical trials or the observational study within WHI. We thus measured the association between polygenic risk for 
medRxiv preprint doi: https://doi.org/10.1101/2021.06.15.21258993; this version posted June 18, 2021. The copyright holder for this preprint (which was not certified by peer review) is the author/funder, who has granted medRxiv a license to display the preprint in perpetuity.

All rights reserved. No reuse allowed without permission.

CAD and blood biomarkers, clinical measurements, clinical risk scores/questionnaires, selfreported medical history, and incident adjudicated outcomes related to cardiovascular disease, cancer, and death.

\section{Methods}

\section{Study cohort}

The study cohort was selected from WHI. The design and recruitment strategy for WHI has been previously described. ${ }^{8,9}$ Briefly, postmenopausal women aged 50 to 79 years were enrolled at 40 sites across the United States from 1993 to 1998. Each participant was enrolled into either a clinical trial $(n=68,132)$ or an observational study $(n=93,676)$. Two successive extension studies continued follow-up of consenting participants from 2005 to 2010 and from 2010 to the present. A subset of participants who were primarily non-Hispanic white by self-report have been previously genotyped as part of 6 ancillary GWAS (Supplementary Table 1). Participants from those 6 GWAS were considered for inclusion in this study. Because currently validated genome-wide PRS were developed in European populations and do not transfer well to nonEuropean populations, we did not include cohorts of primarily non-European genotyped participants in this study. Subjects with a known or likely history of atherosclerotic cardiovascular disease (ASCVD) at enrollment were excluded (Supplementary Table 2).

\section{Genotyping and imputation}

Genotyping was performed with early versions of Affymetrix and Illumina gene chips for five of the GWAS cohorts contributing to this study. For these five studies, harmonization and imputation to the 1000 Genome reference panel was previously performed as part of the WHI 
medRxiv preprint doi: https://doi.org/10.1101/2021.06.15.21258993; this version posted June 18, 2021. The copyright holder for this preprint (which was not certified by peer review) is the author/funder, who has granted medRxiv a license to display the preprint in perpetuity.

All rights reserved. No reuse allowed without permission.

GWAS Harmonization and Imputation Project (https:/www.ncbi.nlm.nih.gov/projects/gap/cgibin/study.cgi?study id=phs000746.v3.p3). Participants of the sixth study were genotyped with the Oncochip, and we imputed these data to the 1000 Genome reference panel using the Michigan Imputation Server. ${ }^{10}$

\section{Main Exposure}

We used metaGRS, a previously developed genome-wide PRS for CAD, to estimate each participant's genetic risk. ${ }^{5}$ This score consists of $\sim 1.7$ million autosomal variants. Participants in our study cohort did not contribute to the GWAS used to construct this score. Each participant's total score was calculated using Plink 2.0, and raw scores were then scaled to mean 0 and standard deviation 1 . This standardize score was used as the primary exposure.

\section{Phenotypes}

Quantitative measurements were largely collected at enrollment and included laboratory values, clinical measurements, and clinical scores. For the small number of lab measurements not collected at baseline, we used the earliest available measurement. For clinical measurements such as blood pressure, the mean value was used if serial measurements were available within one research clinic visit. Self-reported medical history, medication usage, social/behavioral history, and family history was obtained through questionnaires collected primarily at enrollment but also during annual follow up mailings. Adjudicated outcomes assessed in this study include incident cardiovascular diseases, incident cancers, and death. Annual questionnaires were completed by participants or their proxies in order to identify hospitalizations, and for each 
medRxiv preprint doi: https://doi.org/10.1101/2021.06.15.21258993; this version posted June 18, 2021. The copyright holder for this preprint (which was not certified by peer review) is the author/funder, who has granted medRxiv a license to display the preprint in perpetuity.

All rights reserved. No reuse allowed without permission.

hospitalization, medical records were obtained and adjudicated by physicians using standardized criteria. ${ }^{11}$ Deaths were further ascertained through the National Death Index.

\section{Statistical analysis}

We selected the largest subset of subjects with similar inferred genetic ancestry using principal components analysis in order to limit confounding by population substructure. We used linear and logistic regression to estimate associations between each trait/outcome and the CAD PRS per standard deviation increase in the PRS. Each model was adjusted for age at enrollment (or age at time of measurement for lab values) and study type (clinical trial versus observational study). Lab outliers were removed by excluding the top $1 \%$ of values for each biomarker. Associations with lipid-related labs, diabetes-related labs, and for blood pressure were additionally adjusted for self-reported cholesterol medication use, diabetes medication use, and hypertension medication use respectively. All associations with lab values were also adjusted for the assay version if more than one assay was used. For analyses of each of the adjudicated outcomes, we appropriately censored subjects at the end of the follow up time period where formal adjudication ended for the outcome. Regressions were performed using SAS 9.4 (SAS Enterprise). Plots were generated with R version 3.5.1 (R Foundation, Vienna, Austria). All odds ratios (OR) are reported as per standard deviation increase in the PRS.

\section{Results}

We identified 25,789 subjects who had undergone genotyping as part of prior GWAS within the WHI (Supplementary Table 1). When plotting the first two principal components, we noted a cluster of 472 subjects from the GECCO study who were clear outliers (Supplementary Figure 
medRxiv preprint doi: https://doi.org/10.1101/2021.06.15.21258993; this version posted June 18, 2021. The copyright holder for this preprint (which was not certified by peer review) is the author/funder, who has granted medRxiv a license to display the preprint in perpetuity.

All rights reserved. No reuse allowed without permission.

1A). The similar shape between the main cluster and the outliers suggested a batch effect leading to a systematic bias in genotyping calls. These subjects were removed. We then used the Mahalanobis distance ${ }^{12}$ in the remaining subjects to identify a central cluster with similar genetically inferred ancestry (Supplementary Figure 1B). The majority of these subjects selfreported as non-Hispanic white. Lastly, we excluded 2,830 subjects (11\%) with known or likely ASCVD at enrollment (Supplementary Table 2, Figure 1). The remaining cohort of 21,863 subjects showed an enrichment for health traits and outcomes reflective of the genotyping strategy of the parent WHI GWAS, which targeted genotyping for outcomes of interest (Supplementary Table 3). Polygenic risk for CAD was quantified in each of these participants using a validated genome-wide PRS for CAD. ${ }^{5}$

\section{Association of polygenic risk for CAD and quantitative measurements}

We identified 454 blood-based laboratory biomarkers for assessment with PRS after excluding biomarkers with fewer than 100 observations. Lab biomarkers were categorized as being related to lipids $(n=84)$, diabetes $(n=7)$, hormones $(n=93)$, inflammation $(n=62)$, hematology $(n=$ $38)$, or other $(\mathrm{n}=170)$. We further identified 48 clinical exam measurements, 34 quantitative traits reported by questionnaire, and 10 clinical scores. Associations with lipid-related labs, diabetes-related labs, and with blood pressure measurements were adjusted for cholesterol medication use, diabetes medication use, and blood pressure medication use respectively.

Polygenic risk for CAD associated with traits related to traditional risk factors and the metabolic/insulin resistance syndrome. For example, women with a higher PRS tended to have higher systolic blood pressure, larger waist-to-hip ratios, higher fasting insulin, higher lowdensity lipoprotein cholesterol (LDL-C), higher triglycerides and lower high-density lipoprotein 
medRxiv preprint doi: https://doi.org/10.1101/2021.06.15.21258993; this version posted June 18, 2021. The copyright holder for this preprint (which was not certified by peer review) is the author/funder, who has granted medRxiv a license to display the preprint in perpetuity.

All rights reserved. No reuse allowed without permission.

cholesterol (HDL-C) (Figure 2, Supplementary Data). Subjects with a higher PRS also reported less weekly physical activity, and their diets were scored as less healthy. Among lipid measurements, lipoprotein(a) [Lp(a)] showed the most significant association with the CAD PRS. This observation may reflect the very high genetic heritability of Lp(a) levels. ${ }^{13}$ Across multiple lab categories, we observed associations with biomarkers known or hypothesized to relate to CAD risk, including sex hormone binding globulin, ${ }^{14}$ leptin, ${ }^{15}$ hematocrit, ${ }^{16}$ and hepatocyte growth factor. ${ }^{17}$ We also observed a negative association with height, corroborating prior reports that genetically determined shorter stature is associated with a higher risk for CAD. ${ }^{18}$ Analysis of questionnaire data demonstrated that women with higher polygenic risk for CAD tended to report a younger age of their father's and/or mother's death, and they reported experiencing menopause at a younger age. Interestingly, higher polygenic risk for CAD was associated with lower clinically predicted risk for breast cancer using the Gail breast cancer risk model. ${ }^{19}$

\section{Association of polygenic risk for CAD and self-reports}

We aggregated data from structured questionnaires administered at baseline and during regular annual follow up in order to measure the association between polygenic risk for CAD and social/behavioral history, family history, medication usage, and self-reported medical history present at baseline or reported during follow-up. To minimize the risk of ascertainment bias of co-morbidities driven by a diagnosis of CAD, we performed the PRS associations not only in the full set of subjects but also in a subset of participants with no self-reported or adjudicated CAD at the most recent follow-up $(n=18,044)$. Only outcomes with at least 100 cases among the CAD-free cohort were considered, resulting in a total of 128 self-reported qualitative variables. 
medRxiv preprint doi: https://doi.org/10.1101/2021.06.15.21258993; this version posted June 18, 2021. The copyright holder for this preprint (which was not certified by peer review) is the author/funder, who has granted medRxiv a license to display the preprint in perpetuity.

All rights reserved. No reuse allowed without permission.

Figure 3 shows those outcomes which are significant based on a false-discovery rate (FDR) qvalue $\leq 0.05$ in either of the two sets. The complete results are shared in the Supplementary

\section{Data.}

We observed associations between increased polygenic risk for CAD and known risk factors for $\mathrm{CAD}$, in both the full set and the subset with no CAD. For example, among women free of CAD, a higher PRS was associated with a higher likelihood of reporting hypertension (OR 1.2, 95\% CI 1.16-1.25) hypercholesterolemia (OR 1.18, 95\% CI 1.12-1.24), rheumatoid arthritis (OR 1.11, 95\% CI 1.04-1.19), and family history of myocardial infarction (OR 1.16, 95\% CI 1.13-1.20) or stroke (OR 1.07, 95\% CI 1.04-1.11). We also observed an interesting association with smoking. In both the full cohort and the CAD-free cohort, subjects with increased polygenic risk for CAD were slightly less likely to have ever smoked. However, among women who reported having ever smoked, a higher PRS was associated with a higher likelihood of being a current smoker (Figure 3). Possibly related to the association with continued smoking into later adulthood, subjects with increased polygenic risk for CAD were more likely to report a diagnosis of emphysema. Beyond known risk factors, we saw evidence that the genetic drivers of CAD risk may also impact risk for other diseases, including venous thromboembolism (VTE), thyroid disease, and gallbladder-related disease.

We detected an inverse association of the CAD PRS with cancer-related outcomes. Women with higher polygenic risk for CAD were less likely to report a history of breast cancer (OR 0.78, 95\% CI 0.66-0.94) or non-melanoma skin cancer (OR 0.92, 95\% CI 0.87-0.97). They were also less likely to report family history of colon cancer (OR 0.94, 95\% CI 0.90-0.98) and less likely to have ever undergone a colonoscopy (OR 0.96, 95\% CI 0.93-0.99). These associations did not attenuate when analyzing the subset of CAD-free women (Figure 3). 
medRxiv preprint doi: https://doi.org/10.1101/2021.06.15.21258993; this version posted June 18, 2021. The copyright holder for this preprint (which was not certified by peer review) is the author/funder, who has granted medRxiv a license to display the preprint in perpetuity.

All rights reserved. No reuse allowed without permission.

\section{Association of polygenic risk for CAD and incident adjudicated outcomes}

We next aimed to measure the impact of polygenic risk for CAD on incident cardiovascular diseases and cancers by using high-quality adjudicated outcomes from WHI. We identified 17 cardiovascular outcomes and 17 cancer outcomes with at least 100 incident cases among our study cohort. These outcomes represent first-presentation incident events. As expected, outcomes related to CAD showed the strongest associations with the PRS. The more severe manifestations of CAD including myocardial infarction and the need for coronary revascularization demonstrated the strongest effect sizes (Figure 4). A similarly strong association was seen for the first presentation of hospitalized angina ("All angina"). However, the majority of such cases were treated with coronary revascularization. Angina without revascularization demonstrated a comparably weak association that did not reach nominal statistical significance. Non-CAD ASCVD, including stroke, carotid disease, and peripheral arterial disease, demonstrated clear associations with polygenic risk for $\mathrm{CAD}$, though with weaker effect sizes compared to CADrelated outcomes. The association with stroke was driven by the ischemic subtype. We observed no association observed with hemorrhagic stroke. The significant association previously seen with VTE in the self-reported prevalent outcomes (Figure 3) was not reflected in the adjudicated incident outcomes for pulmonary embolus of deep vein thrombosis (Figure 4). Among cancer outcomes, higher polygenic risk for CAD was associated with lower incidence of any cancer, breast cancer, and invasive breast cancer. We also observed a negative association with lung cancer with nominal significance. Associations with other cancer outcomes were not statistically significant, but there was a general systematic trend for ORs $<1$ at a majority of cancers.

The overall impact of polygenic risk for CAD was further observed through analysis of death and survival data. Higher polygenic risk for CAD was associated with lower likelihood of 
medRxiv preprint doi: https://doi.org/10.1101/2021.06.15.21258993; this version posted June 18, 2021. The copyright holder for this preprint (which was not certified by peer review) is the author/funder, who has granted medRxiv a license to display the preprint in perpetuity.

All rights reserved. No reuse allowed without permission.

survival past age 85 (OR 0.94, 95\% CI 0.90-0.98). In total, 11,734 women died during the follow up period, with 78 distinct causes adjudicated. We measured the association between the CAD PRS and 49 causes of death for which at least 10 cases occurred. Figure 5 shows all death outcomes that showed nominal significance. The complete results are available in the

Supplementary Data. The strongest association occurred with 'definite' coronary heart disease death (OR 1.33, 95\% CI 1.20-1.47). Conversely, there was no association with the outcome of 'possible' coronary heart disease death (OR 0.99, 95\% CI 0.91-1.07), suggesting low specificity of that outcome. Despite the observed inverse association with incident breast cancer, we did not find lower risk for breast cancer deaths $(\mathrm{n}=561$, OR 1.04, 95\% CI 0.96-1.14). However, we did appreciate a nominally significant decreased risk for death from melanoma (OR $0.70,95 \% \mathrm{CI}$ 0.51-0.97).

\section{Discussion}

We have shown that polygenic risk for CAD, as quantified by a genome-wide PRS, has broad clinical manifestations in post-menopausal women. In addition to the expected association with CAD and other ASCVD outcomes, we observed associations with biomarkers, clinical measurements, behaviors, and disorders that are known to be risk factors for atherosclerosis. Recent work demonstrated an association between a 300-variant CAD PRS and traditional risk factors among participants of the UK Biobank. ${ }^{6}$ Our analyses corroborate those findings and expand on them significantly by leveraging a genome-wide PRS and an extensively phenotyped population that includes exquisite adjudication for multiple outcomes in the setting of prolonged follow up. Beyond hypertension, hypercholesterolemia, diabetes and obesity, we identify associations related to diet and exercise, and we specifically implicate central adiposity above 
medRxiv preprint doi: https://doi.org/10.1101/2021.06.15.21258993; this version posted June 18, 2021. The copyright holder for this preprint (which was not certified by peer review) is the author/funder, who has granted medRxiv a license to display the preprint in perpetuity.

All rights reserved. No reuse allowed without permission.

weight or BMI as most strongly associated with polygenic risk for CAD in women. We further expand the observed CAD PRS associations to established non-traditional risk factors such as rheumatoid arthritis and elevated $\mathrm{Lp}(\mathrm{a})$, along with several other biomarkers that are relevant to CAD risk. We also highlight the heritable nature of polygenic risk through clear associations with early age of parental death as well as family history of MI and stroke.

We found the effect sizes per standard deviation of CAD PRS for the most severe incident manifestations of CAD (i.e. myocardial infarction and coronary revascularization) to be consistent with the published literature for the same CAD PRS in validation cohorts of European-ancestry men and women combined. ${ }^{5,20}$ One recent study using a different PRS documented heterogeneity in effects sizes between the sexes but did not report or adjust for differences in the severity of disease at presentation among males and females. ${ }^{21}$ Given the substantially lower effect sizes we observed for an angina-only presentation, it is possible that heterogeneity of a PRS between any two groups can be influenced by differences in the case-mix of the severity/type of CAD at presentation. Collectively, the data to date suggest that a large majority of the CAD loci incorporated into the PRS affect a woman's risk of presenting with CAD to the same degree as they do men, even if the average age of presentation may be up to a decade later for women. Importantly, our study offers the opportunity to identify associations that may be specific to women. For example, we found that a higher CAD PRS was associated with younger age of menopause. We cannot determine if this relationship represents a causal mechanism of polygenic risk, but other observational data support the hypothesis that early menopause is a risk factor for CAD. ${ }^{22,23}$ Our biomarker analysis also supports the idea that polygenic risk for CAD influences estrogen biology in women. 
medRxiv preprint doi: https://doi.org/10.1101/2021.06.15.21258993; this version posted June 18, 2021. The copyright holder for this preprint (which was not certified by peer review) is the author/funder, who has granted medRxiv a license to display the preprint in perpetuity.

All rights reserved. No reuse allowed without permission.

The detailed adjudication protocols combined with the large number of outcomes also allowed us to reliably quantify the differences in the magnitude of association of a CAD PRS between CAD and non-CAD manifestations of ASCVD. Our results clearly demonstrate the lower magnitude of associations for intracranial, carotid, and peripheral arterial disease compared to CAD that likely reflect the high but incomplete overlap of genetic risk factors among these various ASCVD-related complications. ${ }^{24}$ We additionally found an association with incident congestive heart failure. This association may be largely attributable to the diagnosis of CAD itself, ${ }^{6}$ and our analysis of self-reported outcomes among subjects with no CAD at follow up (Figure 3) supports this hypothesis.

Somewhat unexpectedly, each of our analyses suggests that increased polygenic risk for CAD is associated with decreased risk for cancer. Women with higher PRS had a lower Gail breast cancer risk score, and they were less likely to report breast cancer, non-melanoma skin cancer, or a family history of colorectal cancer. When we assessed incident adjudicated events, we saw a modest but statistically significant decreased risk for all cancers combined and for breast and invasive breast cancers specifically. With nominal significance, we also saw decreased risk for incident lung cancer and for melanoma as a cause of death. There are several factors that may contribute to these observations. From an epidemiological perspective, this pattern may be effected by competing risks. ${ }^{25}$ Women with high polygenic risk for CAD live shorter lives on average and may be less likely to accrue a cancer diagnosis. It is also plausible that genetic mechanisms that predispose to CAD may protect against some cancers. For example, a higher PRS corresponds to an earlier age of menopause. While early menopause is associated with higher risk for $\mathrm{CAD},{ }^{22,23}$ later menopause is associated with higher risk for breast cancer. ${ }^{26}$ Other mechanisms may also be at play. It is notable that we observed an association with higher 
medRxiv preprint doi: https://doi.org/10.1101/2021.06.15.21258993; this version posted June 18, 2021. The copyright holder for this preprint (which was not certified by peer review) is the author/funder, who has granted medRxiv a license to display the preprint in perpetuity.

All rights reserved. No reuse allowed without permission.

polygenic risk for CAD and shorter stature. It has previously been observed that genetic drivers of taller stature lower risk for CAD and raise risk of cancer. ${ }^{18,27}$

An important limitation of our analysis is that our study population is predominantly white by self-report. To date, CAD PRS have been primarily developed from GWAS in people of European ancestry, and they have been optimized for application to European-ancestry cohorts. This shortcoming remains a barrier to more broadly studying polygenic risk for CAD in diverse populations. With recent efforts to improve representation in $\mathrm{CAD}$ GWAS, ${ }^{7}$ we hope that future PRS research will expand to address this limitation. A second limitation of this work is that our methods do not allow for causal inference. Rather, our results are primarily hypothesisgenerating and/or hypothesis-supporting. We expect that future analyses will be able to further tease out causal mechanisms of the associations we have highlighted here.

In conclusion, polygenic risk for CAD is associated with a broad spectrum of phenotypes. Many of these associations likely reflect the complex pathophysiology of CAD risk, while others may reflect pleiotropic effects beyond CAD. Among WHI participants, higher polygenic risk for CAD was associated with increased risk for multiple forms of incident ASCVD, decreased risk for incident cancer, and increased risk of all-cause mortality. Overall, post-menopausal women with higher polygenic risk for CAD were less likely to live into old age.

\section{Acknowledgments}

The authors thank the WHI (Women's Health Initiative) participants, clinical sites, investigators, and staff for their dedicated efforts. 
medRxiv preprint doi: https://doi.org/10.1101/2021.06.15.21258993; this version posted June 18, 2021. The copyright holder for this preprint (which was not certified by peer review) is the author/funder, who has granted medRxiv a license to display the preprint in perpetuity. All rights reserved. No reuse allowed without permission.

\section{Funding Sources}

The WHI program is funded by the National Heart, Lung, and Blood Institute, National Institutes of Health, U.S. Department of Health and Human Services through contracts 75N92021D00001, 75N92021D00002, 75N92021D00003, 75N92021D00004, 75N92021D00005.

\section{Disclosures}

None 
medRxiv preprint doi: https://doi.org/10.1101/2021.06.15.21258993; this version posted June 18, 2021. The copyright holder for this preprint

\section{References}

1. Khera AV, Kathiresan S. Genetics of coronary artery disease: discovery, biology and clinical translation. Nat Rev Genet 2017;18:331-344. doi:10.1038/nrg.2016.160.

2. van der Harst P, Verweij N. Identification of 64 Novel Genetic Loci Provides an Expanded View on the Genetic Architecture of Coronary Artery Disease. Circ Res 2018;122:433-443. doi:10.1161/CIRCRESAHA.117.312086.

3. Koyama S, Ito K, Terao C, Akiyama M, Horikoshi M, Momozawa Y, et al. Populationspecific and trans-ancestry genome-wide analyses identify distinct and shared genetic risk loci for coronary artery disease. Nat Genet 2020;52:1169-1177. doi:10.1038/s41588-0200705-3.

4. Khera AV, Chaffin M, Aragam KG, Haas ME, Roselli C, Choi SH, et al. Genome-wide polygenic scores for common diseases identify individuals with risk equivalent to monogenic mutations. Nat Genet 2018;50:1219-1224. doi:10.1038/s41588-018-0183-z.

5. Inouye M, Abraham G, Nelson CP, Wood AM, Sweeting MJ, Dudbridge F, et al. Genomic Risk Prediction of Coronary Artery Disease in 480,000 Adults: Implications for Primary Prevention. J Am Coll Cardiol 2018;72:1883-1893. doi:10.1016/j.jacc.2018.07.079.

6. Ntalla I, Kanoni S, Zeng L, Giannakopoulou O, Danesh J, Watkins H, et al. Genetic Risk Score for Coronary Disease Identifies Predispositions to Cardiovascular and Noncardiovascular Diseases. J Am Coll Cardiol 2019;73:2932-2942. doi:10.1016/j.jacc.2019.03.512.

7. Tcheandjieu C, Zhu X, Hilliard A, Clarke SL, Napolioni V, Ma S, et al. A large-scale multiethnic genome-wide association study of coronary artery disease. Preprint 2021;Research Square. doi:10.21203/rs.3.rs-275591/v1.

8. Design of the Women's Health Initiative clinical trial and observational study. The Women's Health Initiative Study Group. Control Clin Trials 1998;19:61-109. doi:10.1016/s01972456(97)00078-0.

9. Hays J, Hunt JR, Hubbell FA, Anderson GL, Limacher M, Allen C, et al. The Women's Health Initiative recruitment methods and results. Ann Epidemiol 2003;13:S18-77. doi:10.1016/s1047-2797(03)00042-5.

10. Das S, Forer L, Schönherr S, Sidore C, Locke AE, Kwong A, et al. Next-generation genotype imputation service and methods. Nat Genet 2016;48:1284-1287. doi:10.1038/ng.3656.

11. Curb JD, McTiernan A, Heckbert SR, Kooperberg C, Stanford J, Nevitt M, et al. Outcomes ascertainment and adjudication methods in the Women's Health Initiative. Ann Epidemiol 2003;13:S122-128. doi:10.1016/s1047-2797(03)00048-6.

12. Luu K, Bazin E, Blum MGB. pcadapt: an R package to perform genome scans for selection based on principal component analysis. Mol Ecol Resour 2017;17:67-77. doi:10.1111/17550998.12592. 
medRxiv preprint doi: https://doi.org/10.1101/2021.06.15.21258993; this version posted June 18, 2021. The copyright holder for this preprint (which was not certified by peer review) is the author/funder, who has granted medRxiv a license to display the preprint in perpetuity.

13. Austin MA, Sandholzer C, Selby JV, Newman B, Krauss RM, Utermann G. Lipoprotein(a) in women twins: heritability and relationship to apolipoprotein(a) phenotypes. Am J Hum Genet 1992;51:829-840.

14. Rexrode KM, Manson JE, Lee I-M, Ridker PM, Sluss PM, Cook NR, et al. Sex hormone levels and risk of cardiovascular events in postmenopausal women. Circulation 2003;108:1688-1693. doi:10.1161/01.CIR.0000091114.36254.F3.

15. Kk K, Sm P, Mj Q. Leptin and cardiovascular disease: response to therapeutic interventions. Circulation 2008;117. doi:10.1161/CIRCULATIONAHA.107.741645.

16. Gagnon DR, Zhang TJ, Brand FN, Kannel WB. Hematocrit and the risk of cardiovascular disease--the Framingham study: a 34-year follow-up. Am Heart J 1994;127:674-682. doi:10.1016/0002-8703(94)90679-3.

17. Bell EJ, Decker PA, Tsai MY, Pankow JS, Hanson NQ, Wassel CL, et al. Hepatocyte growth factor is associated with progression of atherosclerosis: The Multi-Ethnic Study of Atherosclerosis (MESA). Atherosclerosis 2018;272:162-167. doi:10.1016/j.atherosclerosis.2018.03.040.

18. Nelson CP, Hamby SE, Saleheen D, Hopewell JC, Zeng L, Assimes TL, et al. Genetically determined height and coronary artery disease. N Engl J Med 2015;372:1608-1618. doi:10.1056/NEJMoa1404881.

19. Gail MH, Brinton LA, Byar DP, Corle DK, Green SB, Schairer C, et al. Projecting individualized probabilities of developing breast cancer for white females who are being examined annually. J Natl Cancer Inst 1989;81:1879-1886. doi:10.1093/jnci/81.24.1879.

20. Dikilitas O, Schaid DJ, Kosel ML, Carroll RJ, Chute CG, Denny JA, et al. Predictive Utility of Polygenic Risk Scores for Coronary Heart Disease in Three Major Racial and Ethnic Groups. Am J Hum Genet 2020;106:707-716. doi:10.1016/j.ajhg.2020.04.002.

21. Huang Y, Hui Q, Gwinn M, Hu Y-J, Quyyumi AA, Vaccarino V, et al. Sexual Differences in Genetic Predisposition of Coronary Artery Disease. Circ Genomic Precis Med 2021;14:e003147. doi:10.1161/CIRCGEN.120.003147.

22. Hu FB, Grodstein F, Hennekens CH, Colditz GA, Johnson M, Manson JE, et al. Age at natural menopause and risk of cardiovascular disease. Arch Intern Med 1999;159:10611066. doi:10.1001/archinte.159.10.1061.

23. Honigberg MC, Zekavat SM, Aragam K, Finneran P, Klarin D, Bhatt DL, et al. Association of Premature Natural and Surgical Menopause With Incident Cardiovascular Disease. JAMA 2019. doi:10.1001/jama.2019.19191.

24. Klarin D, Lynch J, Aragam K, Chaffin M, Assimes TL, Huang J, et al. Genome-wide association study of peripheral artery disease in the Million Veteran Program. Nat Med 2019;25:1274-1279. doi:10.1038/s41591-019-0492-5.

25. Cornfield J. The estimation of the probability of developing a disease in the presence of competing risks. Am J Public Health Nations Health 1957;47:601-607. doi:10.2105/ajph.47.5.601.

26. Collaborative Group on Hormonal Factors in Breast Cancer. Menarche, menopause, and breast cancer risk: individual participant meta-analysis, including 118964 women with 
medRxiv preprint doi: https://doi.org/10.1101/2021.06.15.21258993; this version posted June 18, 2021. The copyright holder for this preprint (which was not certified by peer review) is the author/funder, who has granted medRxiv a license to display the preprint in perpetuity. All rights reserved. No reuse allowed without permission.

breast cancer from 117 epidemiological studies. Lancet Oncol 2012;13:1141-1151. doi:10.1016/S1470-2045(12)70425-4.

27. Ong J-S, An J, Law MH, Whiteman DC, Neale RE, Gharahkhani P, et al. Height and overall cancer risk and mortality: evidence from a Mendelian randomisation study on 310,000 UK Biobank participants. Br J Cancer 2018;118:1262-1267. doi:10.1038/s41416-018-0063-4. 


\section{Figures}

\section{Women's Health Initiative Clinical Trials and Observational Study cohort \\ 161,808}

Participants genotyped as part of 6 prior genome-wide association studies

\section{5,789}

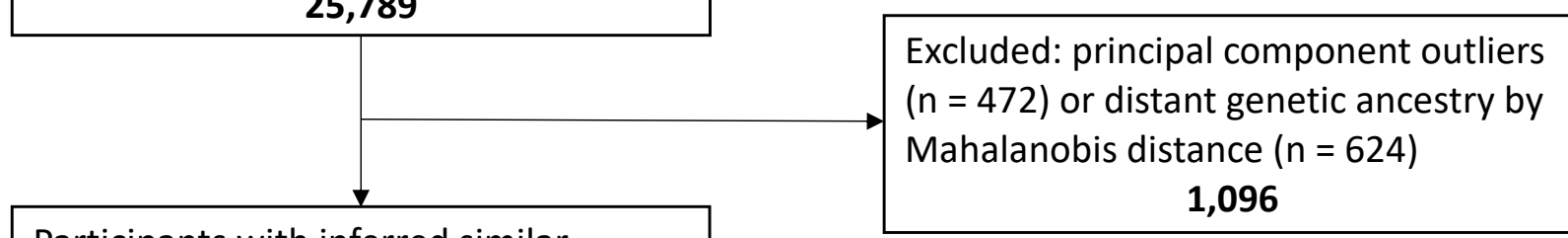

Participants with inferred similar genetic ancestry by principal components analysis

24,693

Participants with no history of atherosclerotic cardiovascular disease at enrollment

\section{1,863}

Excluded: known or likely atherosclerotic cardiovascular disease at enrollment 2,830

Figure 1. Flow diagram of Women's Health Initiative subjects selected for this study. 


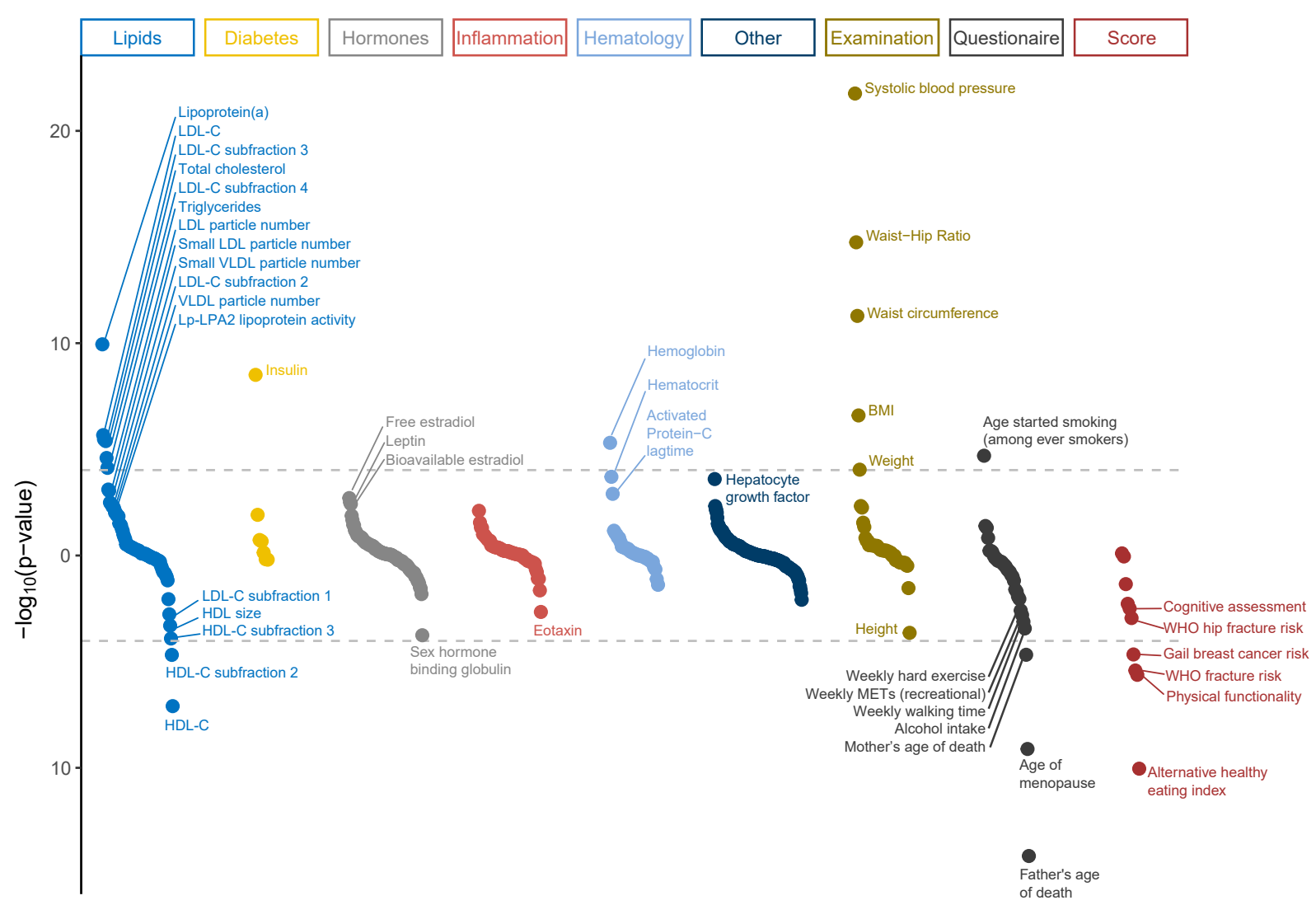

Figure 2. Associations between polygenic risk for coronary artery disease and quantitative traits derived from lab values, clinical exam, self-report, and clinical scores. Positive associations are plotted in the up direction and negative associations are plotted in the down direction. Associations that are significant with FDR q-value $\leq 0.05$ are labeled. The horizontal gray dashed lines represent the Bonferroni significant $p$-value $\leq 9.2 \times 10^{-5}(0.05 / 546)$. 


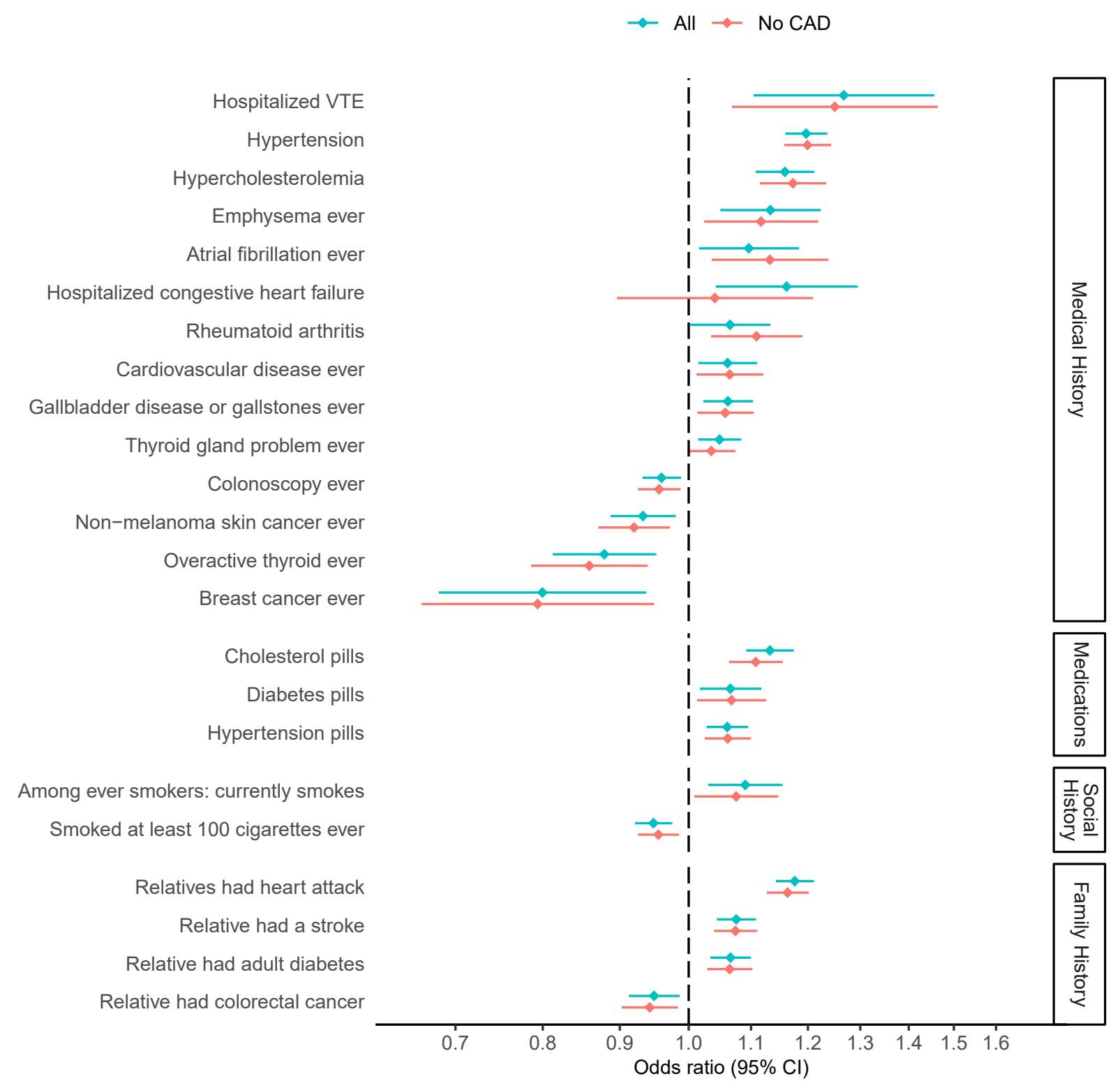

Figure 3. Associations between polygenic risk for coronary artery disease (CAD) and self-reported history, collected at baseline and follow up. Associations within the full study cohort are compared to the subset with no CAD at follow up. Only outcomes with at least 100 cases in the CAD-free group were considered (128 outcomes). The plot shows all outcomes that were significant with FDR q-value $\leq 0.05$ in either of the two groups. 


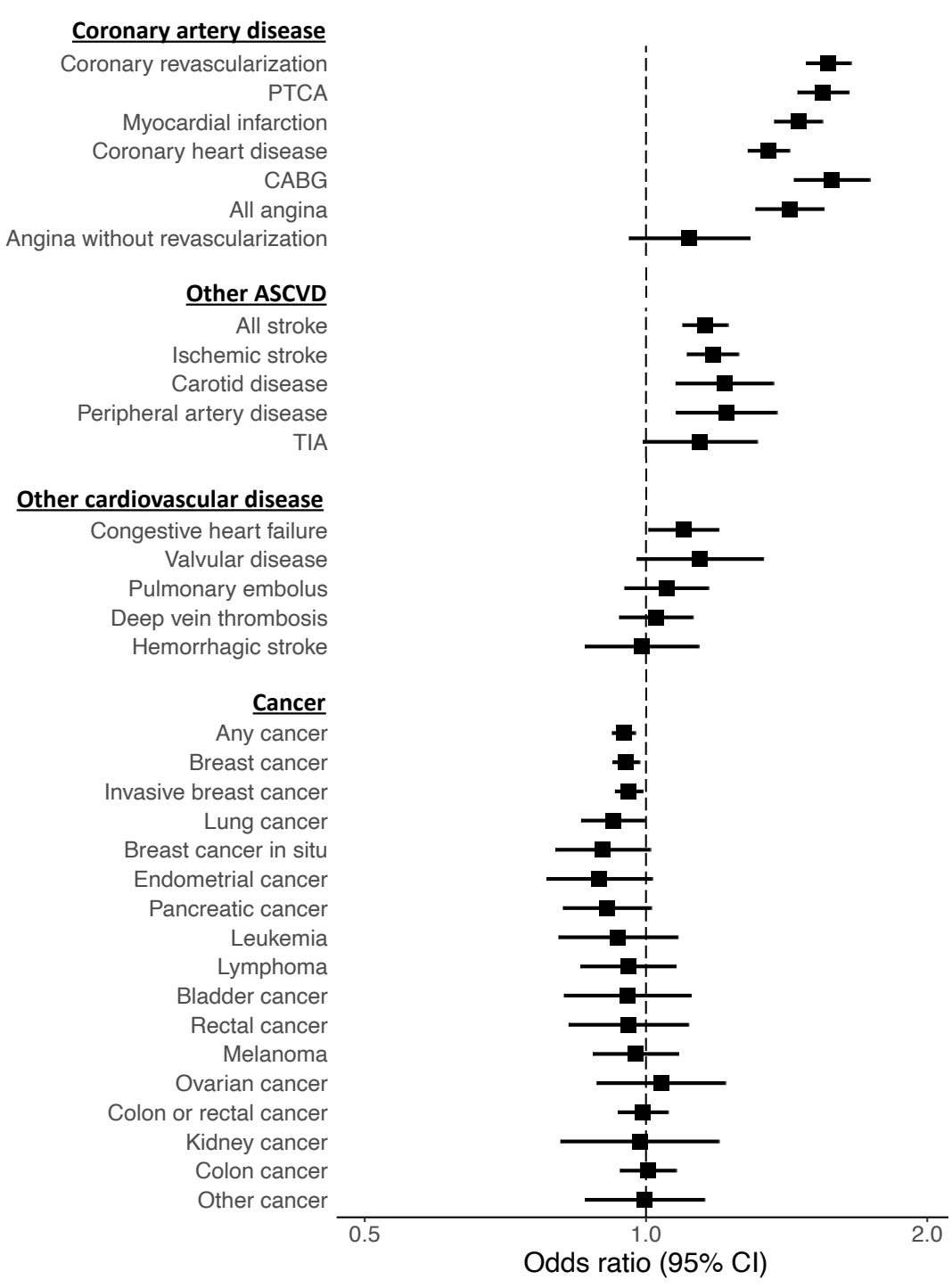

Coronary artery disease

Myocardial infarction

CABG

All angina

Angina without revascularization

\section{Other ASCVD}

Ischemic stroke

Carotid disease

.

ongestive heart failure

Pulmonary embolus

Deep vein thrombosis

Hemorrhagic stroke

$$
\text { Any cancer }
$$

vasive breast cancer

Endometrial cance

Pancreatic cancer

Leukemia

Rectal cancer

Melanoma

Kidney cancer

Colon cancer

Odds ratio $(95 \% \mathrm{Cl})$
Cases Controls OR $(95 \% \mathrm{Cl})$

$\begin{array}{rlll}1,530 & 20,333 & 1.57(1.48-1.66) & 1.2 \mathrm{E}-56^{* *} \\ 1,150 & 20,713 & 1.55(1.45-1.65) & 6.5 \mathrm{E}-42^{* *} \\ 1,309 & 20,554 & 1.46(1.37-1.54) & 2.4 \mathrm{E}-35^{* *} \\ 1,792 & 20,071 & 1.35(1.29-1.42) & 8.4 \mathrm{E}-31 * * \\ 501 & 21,362 & 1.58(1.44-1.74) & 7.4 \mathrm{E}-22 * * \\ 620 & 21,243 & 1.42(1.31-1.55) & 1.6 \mathrm{E}-16 * *\end{array}$

$191 \quad 21,243 \quad 1.11(0.96-1.29) \quad 0.16$

$\begin{array}{rrrc}1,457 & 20,406 & 1.16(1.09-1.22) & 3.2 \mathrm{E}-07^{* *} \\ 1,108 & 20,755 & 1.18(1.11-1.26) & 3.9 \mathrm{E}-07^{* *} \\ 293 & 21,570 & 1.21(1.08-1.37) & 1.7 \mathrm{E}-03^{*} \\ 275 & 21,588 & 1.22(1.08-1.38) & 1.8 \mathrm{E}-03^{*} \\ 213 & 21,650 & 1.14(0.99-1.32) & 6.4 \mathrm{E}-02\end{array}$

$579 \quad 21,284 \quad 1.10(1.01-1.20) \quad 3.6 \mathrm{E}-02$

$174 \quad 21,689 \quad 1.14(0.98-1.33) \quad 9.4 \mathrm{E}-02$

$399 \quad 21,464 \quad 1.05(0.95-1.17) \quad 0.34$

$\begin{array}{llll}519 & 21,344 & 1.03(0.94-1.12) & 0.59\end{array}$

$214 \quad 21,649 \quad 0.99(0.86-1.14) \quad 0.88$

$8,294 \quad 13,569 \quad 0.95(0.92-0.97) \quad 1.6 \mathrm{E}-04 * *$

$4,928 \quad 16,935 \quad 0.95(0.92-0.98) \quad 3.9 \mathrm{E}-03 *$

$4,686 \quad 17,177 \quad 0.96(0.93-0.99) \quad 1.4 \mathrm{E}-02 *$

$696 \quad 21,167 \quad 0.92(0.85-1.00) \quad 4.3 \mathrm{E}-02$

$309 \quad 21,554 \quad 0.90(0.80-1.01) \quad 7.5 \mathrm{E}-02$

$248 \quad 21,615 \quad 0.89(0.78-1.02) \quad 8.3 \mathrm{E}-02$

$358 \quad 21,505 \quad 0.91(0.82-1.01) \quad 8.4 \mathrm{E}-02$

$\begin{array}{llll}195 & 21,668 & 0.93(0.81-1.08) & 0.36\end{array}$

$307 \quad 21,556 \quad 0.96(0.85-1.08) \quad 0.46$

$\begin{array}{llll}172 & 21,691 & 0.96(0.82-1.12) & 0.56\end{array}$

$193 \quad 21,670 \quad 0.96(0.83-1.11) \quad 0.57$

$\begin{array}{llll}383 & 21,480 & 0.97(0.88-1.08) & 0.63\end{array}$

$\begin{array}{llll}168 & 21,695 & 1.04(0.89-1.22) & 0.65\end{array}$

$1,151 \quad 20,712 \quad 0.99(0.93-1.06) \quad 0.81$

$\begin{array}{llll}110 & 21,753 & 0.98(0.81-1.20) & 0.88\end{array}$

$910 \quad 20,953 \quad 1.01(0.94-1.08) \quad 0.88$

$194 \quad 21,669 \quad 1.00(0.86-1.16) \quad 0.97$

Figure 4. Associations between polygenic risk for coronary artery disease and incident adjudicated outcomes related to cardiovascular diseases and cancers in the Women's Health Initiative. Outcomes with at least 100 incident cases were considered, resulting in 17 cardiovascular outcomes and 17 cancer outcomes. Outcomes with a single asterisk are significant with an FDR q-value $\leq 0.05$. Outcomes with double asterisks have a Bonferroni significant $\mathrm{p}$-value $\leq 1.5 \times 10^{-3}(0.05 / 34)$. PTCA $=$ Percutaneous Transluminal Coronary Angioplasty CABG $=$ Coronary Artery Bypass Graft; ASCVD $=$ Atherosclerotic Cardiovascular Disease; TIA = Transient Ischemic Attack 


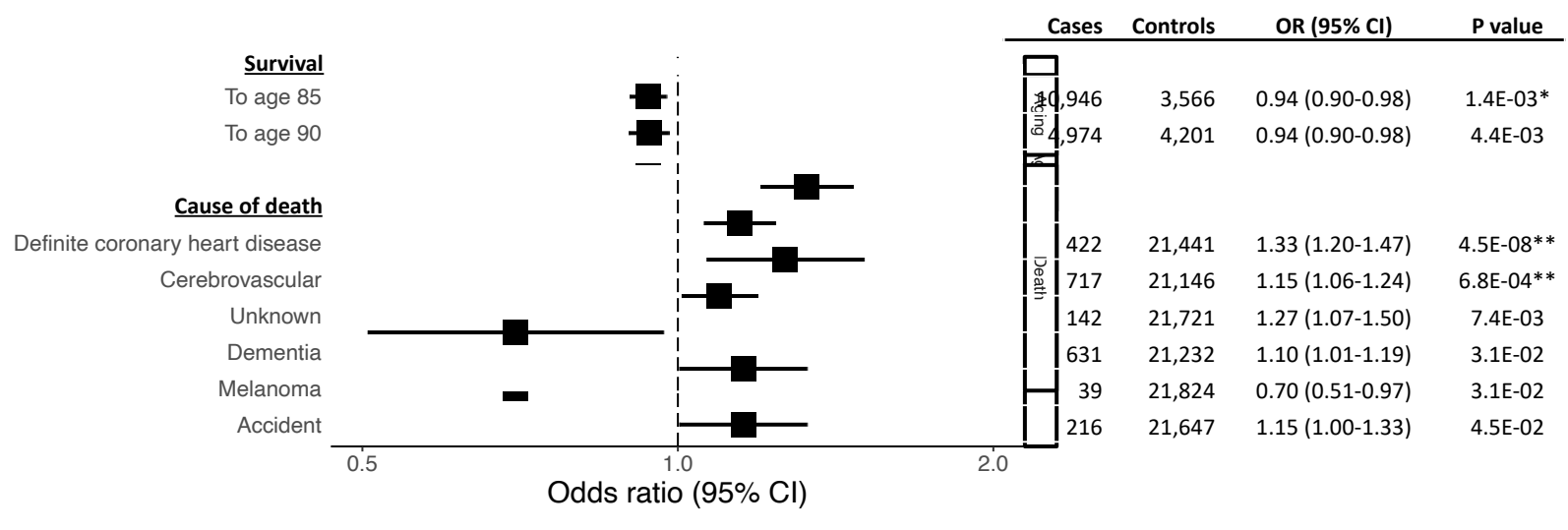

Figure 5. Associations between polygenic risk for coronary artery disease and death outcomes in the Women's Health Initiative. Outcomes with at least 10 cases were considered, resulting in 53 outcomes. All associations with nominal statistical significance are shown. Outcomes with a single asterisk are significant with an FDR q-value $\leq 0.05$. Outcomes with double asterisks have a Bonferroni significant $p$-value $\leq 9.4 \times 10^{-4}(0.05 / 53)$. 